\title{
Germination of Primed Seed under NaCl Stress in Wheat
}

\author{
Michael P. Fuller, ${ }^{1}$ Jalal H. Hamza, ${ }^{1,2}$ Hail Z. Rihan, ${ }^{1}$ and Mohammad Al-Issawi ${ }^{1}$ \\ ${ }^{1}$ School of Biomedical and Biological Sciences, Faculty of Science and Technology, Plymouth University, Plymouth PL4 8AA, UK \\ ${ }^{2}$ Department of Agronomy, College of Agriculture, University of Baghdad, Baghdad, Iraq
}

Correspondence should be addressed to Michael P. Fuller, mfuller@plymouth.ac.uk

Received 5 October 2012; Accepted 7 November 2012

Academic Editors: F. A. Culianez-Macia and A. W. Woodward

Copyright ( $) 2012$ Michael P. Fuller et al. This is an open access article distributed under the Creative Commons Attribution License, which permits unrestricted use, distribution, and reproduction in any medium, provided the original work is properly cited.

Soil salinity affects a large and increasing amount of arable land worldwide, and genetic and agronomic solutions to increasing salt tolerance are urgently needed. Experiments were conducted to improve wheat seed performance under salinity stress conditions after priming. An experiment was conducted using a completely randomized design of four replications for germination indices in wheat (Triticum aestivum L. cv. Caxton). Normal and primed seed with $\mathrm{PEG}_{6000}$ at $-1 \mathrm{MPa}$ and five concentrations of $\mathrm{NaCl}(0,50$, $100,150$, and $200 \mathrm{mM})$ were tested. Results indicate that priming seed significantly $(P<0.05)$ increased germination percentage at first count and final count, coefficient of velocity of germination, germination rate index, and mean germination time, while increasing of $\mathrm{NaCl}$ concentration significantly reduced it. Priming seed improved germination attributes at all $\mathrm{NaCl}$ concentration levels. The priming appeared to be able to overcome the effect of salt stress at 50 to $100 \mathrm{mM}$ and reduce the effect of $\mathrm{NaCl}$ at higher concentrations up to $200 \mathrm{mM}$. The primed seed gave both faster germination and led to higher germination when under salt stress. We conclude that using priming techniques can effectively enhance the germination seed under saline condition.

\section{Introduction}

Salinity is a major limiting factor in crop productivity all over the world. Salinity affects plant growth at all developmental stages; however, sensitivity varies from one growth stage to another. Germination is a critical stage of the plant cycle and improved tolerance of high salinity could improve the stability of plant production [1]. Water is osmotically held in salt solutions. Therefore, the salt concentration completely inhibits germination at higher levels or induces a state of dormancy at low levels, it also reduces imbibition of water because of lowered osmotic potentials of the medium and causes changes in metabolic activity [2].

For the maintenance of high yield of crops under salt stressed conditions, various research tools are being tried to counteract the effects of salinity. Seed priming treatments are simply applied practices that can reduce the effects of salinity with small inputs of capital and energy. Many such seed priming or invigoration treatments are being used to improve the rate and speed of germination under stressed conditions or with substandard seed lots [3]. Pre-sowing treatments such as priming techniques with different salts, water, and osmoprotectants assist the germination and establishment process in the field [4]. Priming of seeds with $\mathrm{CaCl}_{2}$, followed by priming with $\mathrm{KCl}$ and $\mathrm{NaCl}$, were found to be effective in alleviating the adverse effects of salt stress on wheat plants through their effects on altering the levels of different plant phytohormones [5]. Khan et al. [6] observed that priming of seeds using $\mathrm{NaCl}$ improved seedling vigour and establishment under salt stress conditions. Seed priming improves seed performance by encouraging rapid, uniform, and vigorous germination which helps seedlings to grow in stressed conditions $[4,7,8]$. Similarly, Jafar et al. demonstrated that seed priming could be used successfully to assist the germination of wheat in the field [9].

The analysis of physiological changes in plants associated with seed-priming may be useful for advancing the understanding of plant salt tolerance and may suggest strategies by which plants acquire or alter their salt tolerance. The primary objective of the present study was to determine the effect of priming on seedling growth and to determine if the mechanism of activation of seeds may be used as a technique 
to increase the viability of the seed to perform better under excess salinity.

\section{Methods}

The experiment was conducted at the School of Biomedical and Biological Sciences, Plymouth University, UK, in 2011, to determine if a seed priming technique can enhance the seed tolerance to salinity stress. An experiment was conducted with wheat (Triticum aestivum L. cv. Caxton) using a completely randomized design of four replications. Normal and primed seed with $\mathrm{PEG}_{6000}$ at $-1 \mathrm{MPa}$ and five concentrations of $\mathrm{NaCl}(0,50,100,150$, and $200 \mathrm{mM})$ were tested.

The primed solution $(-1 \mathrm{MPa})$ was prepared by dissolving $21.9 \mathrm{~g} \mathrm{PEG} / 100 \mathrm{~mL}$ of $\mathrm{PEG}_{6000}$ in distilled water at $20^{\circ} \mathrm{C}$ and confirmed using an OSMOMET device. Seeds (250 g) for each treatment were immersed in $300 \mathrm{~mL}$ of the priming solution for $6 \mathrm{~h}$ in plastic containers covered with lids to prevent evaporation loss. After priming, the seed samples were removed and rinsed several times in tap water and then dried back to the original moisture level of $12 \%$ by subjecting the seed to $20 \pm 1^{\circ} \mathrm{C}$ and $50 \% \mathrm{RH}$ for $24 \mathrm{~h}$. A digital Protimeter was used for measuring and monitoring the moisture content during the drying period. Fifty seeds from each treatment were placed in $140 \mathrm{~mm}$ diameter petri dishes on two layers of Whatman no.1 filter paper moistened with $40 \mathrm{~mL}$ of the appropriate salt test solutions $(0,50,100$, 150 , and $200 \mathrm{mM}$ of $\mathrm{NaCl}$ ). The petri dishes were placed in an incubator at $20 \pm 1^{\circ} \mathrm{C}$ under dark conditions to germinate. Seeds were considered to be germinated when they exhibited a radicle extension longer than $2 \mathrm{~mm}$. The germination count was recorded daily up to 8 days. From the germination counts several germination attributes were studied to investigate the effect of the priming on salt tolerance including germination percentage (\%) as first count after 4 days (FG), germination percentage (\%) as final count after 8 days (LG), coefficient of velocity of germination (CVG), and germination rate index (GRI), mean germination time (MGT) as follow:

$$
\operatorname{CVG}\left(\% \text { day }^{-1}\right)=\frac{\sum N i}{\sum(N i T i)} \times 100
$$

(see $[10])$,

$$
\text { GRI }\left(\% \text { day }^{-1}\right)=\sum\left(\frac{N i}{i}\right)
$$

(see $[11])$,

$$
\operatorname{MGT}(d)=\frac{\sum(N i T i)}{\sum N i}
$$

(see $[11])$, where $N$ is the number of seeds germinated on day $i$, and $T i$ is the number of days from sowing.

The CVG gives an indication of the rapidity of germination. It increases when the number of germinated seeds increases and the time required for germination decreases. Theoretically, the highest CVG possible is 100 . This would occur if all seeds germinated on the first day [10]. The GRI reflects the percentage of germination on each day of the germination period. Higher GRI values indicate higher and faster germination [11]. The lower MGT, the faster a population of seeds has germinated [11].

2.1. Statistical Analysis. All data were subjected to analysis of variance (ANOVA) using SPSS software (version 17), and comparisons of means were made using the least significant difference test (LSD) at $P<0.05$ level of confidence. Calculated coefficients of simple correlation between attributes were also studied [12].

\section{Results}

3.1. ANOVA. Analyses of variance showed significant effects of priming and $\mathrm{NaCl}$ concentrations on attributes of germination (Table 1). The effects of the $\mathrm{NaCl}$ concentrations accounted for a high proportion of the variance in all analyses. There was no significant interaction effect in any of the attributes of germination.

3.2. The Effect of Priming and $\mathrm{NaCl}$ Concentration. Priming seed with $\mathrm{PEG}_{6000}$ at $-1 \mathrm{MPa}$ significantly increased the attributes of germination compared with normal seed (Table 2) and increasing $\mathrm{NaCl}$ concentration significantly reduced the attributes of germination compared with control treatment $(0 \mathrm{NaCl})$.

Priming seed improved germination at all of $\mathrm{NaCl}$ concentration levels compared with normal seed (Figure 1) and showed that the pattern of response to $\mathrm{NaCl}$ concentrations were the same for normal and primed seed. The primed seed gave both faster germination (FG, CVG, GRI, and MGT) and led to higher germination (LG) when under salt stress (Figure 1).

Increasing salt stress reduced the speed of germination and the germination rate. For normal seed this was evident at $50 \mathrm{mM} \mathrm{NaCl}$ and got progressively worse at each increment of salt applied (Figure 1). Whilst speed of germination was affected by each increment of salt (FG, CVG, GRI, and MGT) and salt significantly reduced the final germination (LG) above $100 \mathrm{mM} \mathrm{NaCl}$. For primed seed, speed of germination was affected by each increment of salt above $50 \mathrm{mM} \mathrm{NaCl}$ (FG, CVG, GRI, and MGT), and salt significantly reduced the final germination (LG) above $100 \mathrm{mM} \mathrm{NaCl}$.

3.3. Correlation between Attributes. Positive highly significant correlations $(P<0.001)$ were found between FG, LG, CVG, and GRI, and negative highly significant correlations $(P<0.001)$ were found between each of FG, LG, CVG, and GRI, and MGT (Table 3).

\section{Discussion}

The application of increasing salt stress had substantial negative effects on all the attributes investigated with an overall negative effect on germination. The values of FG, LG, CVG, and GRI were decreased, while the time required 


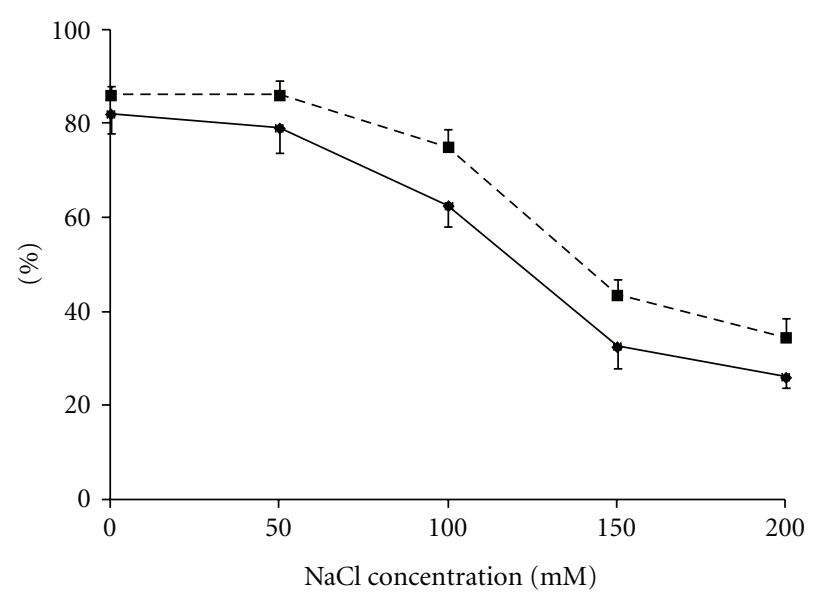

(a) First germination after 4 days (FG)

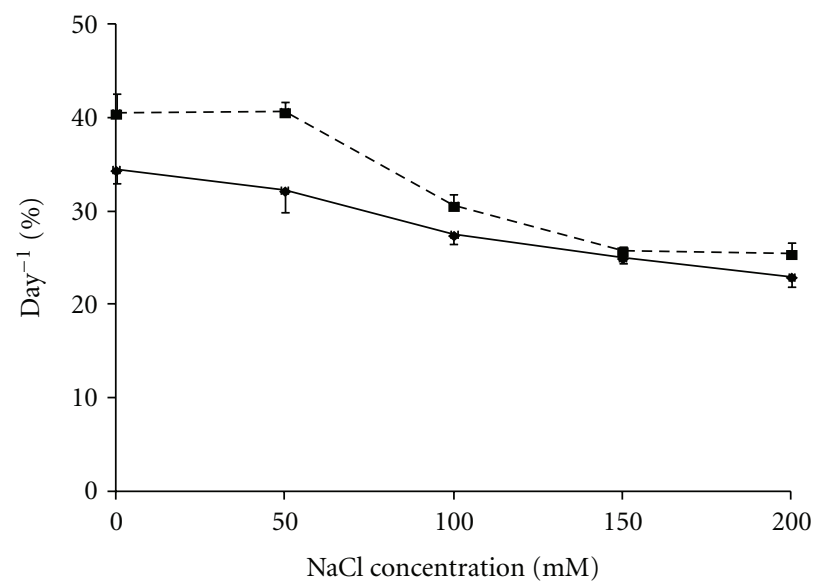

(c) Coefficient of velocity of germination (CVG)

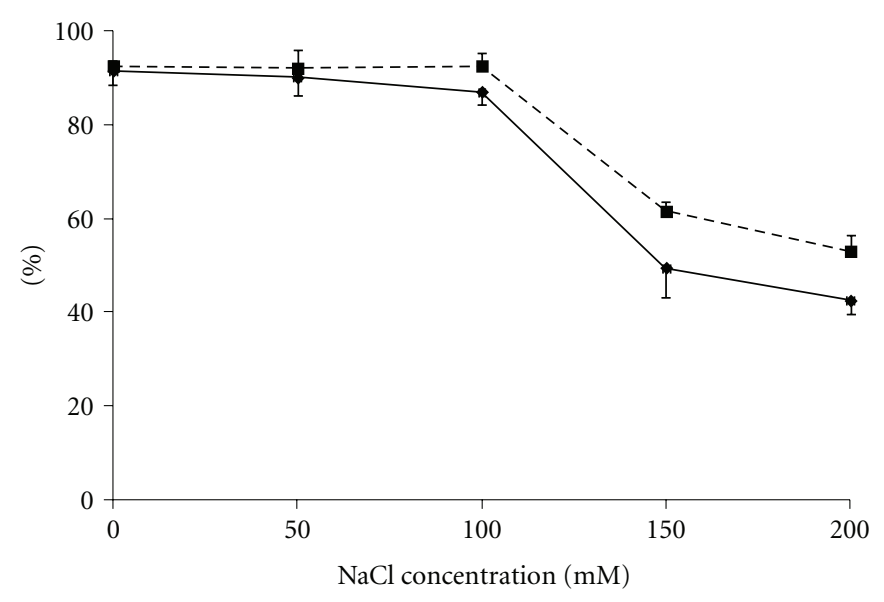

(b) Final germination after 8 days (LG)

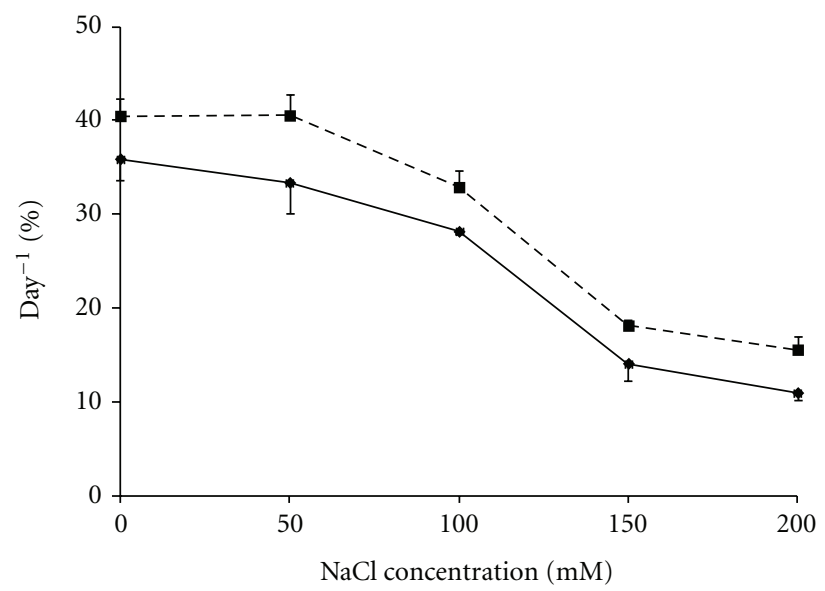

(d) Germination rate index (GRI)

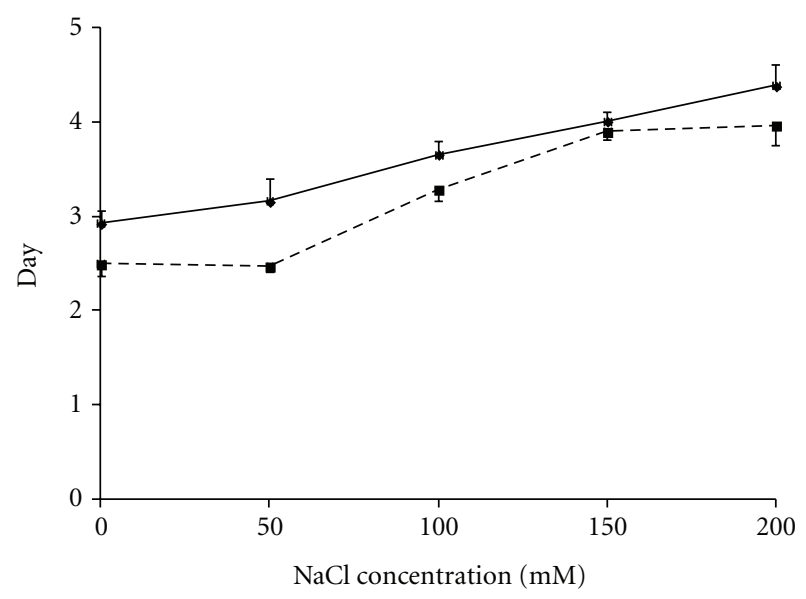

(e) Mean germination time (MGT)

FIGURE 1: Interaction priming $\times \mathrm{NaCl}$ concentration for attributes of germination, (a) FG (b) LG, (c) CVG, (d) GRI, and (e) MGT. Primed seed with $\mathrm{PEG}_{6000}$ at $-1 \mathrm{MPa}$ (dotted lines) and normal seed (solid lines). Vertical bars indicate SE.

to obtain a faster germination (MGT) was increased. This study showed significant negative relationships between the concentration of sodium chloride and between most of the germination attributes and a positive relationship with MGT. This agrees with other observations in wheat, where salinity has been shown to negatively affect the rate of starch remobilization by causing a decrease in $\alpha$-amylase activity [13].

The results also showed that priming of wheat seeds with $\mathrm{PEG}_{6000}$ at $-1 \mathrm{MPa}$ can have significant improvements 
TABLE 1: Analysis of variance for effect of priming and $\mathrm{NaCl}$ concentration on attributes of germination.

\begin{tabular}{|c|c|c|c|c|c|c|}
\hline \multirow{2}{*}{\multicolumn{2}{|c|}{ df }} & \multicolumn{5}{|c|}{ Mean square } \\
\hline & & FG & LG & CVG & GRI & MGT \\
\hline Priming & 1 & $739.60^{* *}$ & $384.40^{* *}$ & $171.304^{* *}$ & $250.50^{* *}$ & $1.63642^{* *}$ \\
\hline $\mathrm{NaCl}$ concentration & 4 & $5050.85^{* *}$ & $3770.35^{* *}$ & $302.104^{* *}$ & $1089.44^{* *}$ & $3.45680^{* *}$ \\
\hline Priming $\times \mathrm{NaCl}$ concentration & 4 & $22.35^{\text {ns }}$ & $48.65^{\mathrm{ns}}$ & $18.698^{\mathrm{ns}}$ & $3.00^{\mathrm{ns}}$ & $0.08384^{\mathrm{ns}}$ \\
\hline Error & 30 & 58.53 & 47.80 & 7.489 & 13.85 & 0.09563 \\
\hline $\mathrm{CV}(\%)$ & & 12.6 & 9.2 & 9.0 & 13.8 & 9.0 \\
\hline
\end{tabular}

** Significant at $P<0.01,{ }^{\text {ns }}$ Not significant.

TABle 2: Means comparison of the effect of priming and $\mathrm{NaCl}$ concentration on attributes of germination.

\begin{tabular}{|c|c|c|c|c|c|}
\hline \multirow{2}{*}{ Treatment } & \multicolumn{5}{|c|}{ Attributes of germination } \\
\hline & FG & LG & CVG & GRI & MGT \\
\hline Primed seed $\left(\mathrm{PEG}_{6000}\right.$ at $\left.-1 \mathrm{MPa}\right)$ & $65.0^{\mathrm{a}}$ & $78.3^{\mathrm{a}}$ & $32.5^{\mathrm{a}}$ & $29.5^{\mathrm{a}}$ & $3.2^{\mathrm{a}}$ \\
\hline Normal seeds & $56.4^{\mathrm{b}}$ & $72.1^{\mathrm{b}}$ & $28.4^{\mathrm{b}}$ & $24.5^{\mathrm{b}}$ & $3.6^{\mathrm{b}}$ \\
\hline \multicolumn{6}{|l|}{$\mathrm{NaCl}$ concentration $(\mathrm{mM})$} \\
\hline 0 & $84.0^{\mathrm{a}}$ & $92.0^{\mathrm{a}}$ & $37.4^{\mathrm{a}}$ & $38.2^{\mathrm{a}}$ & $2.7^{\mathrm{a}}$ \\
\hline 50 & $82.5^{\mathrm{a}}$ & $91.0^{\mathrm{a}}$ & $36.4^{\mathrm{a}}$ & $37.0^{\mathrm{a}}$ & $2.8^{\mathrm{a}}$ \\
\hline 100 & $68.8^{\mathrm{b}}$ & $89.8^{\mathrm{a}}$ & $29.0^{\mathrm{b}}$ & $30.5^{\mathrm{b}}$ & $3.5^{\mathrm{b}}$ \\
\hline 150 & $38.0^{c}$ & $55.5^{\mathrm{b}}$ & $25.4^{\mathrm{c}}$ & $16.1^{\mathrm{c}}$ & $4.0^{c}$ \\
\hline 200 & $30.2^{\mathrm{c}}$ & $47.8^{\mathrm{c}}$ & $25.2^{\mathrm{c}}$ & $13.3^{\mathrm{c}}$ & $4.2^{\mathrm{c}}$ \\
\hline
\end{tabular}

Means within a column with common characters are not significant at $P<$ 0.05 .

TABLE 3: Correlation coefficients between attributes of germination.

\begin{tabular}{lcccc}
\hline & MGT & GRI & CVG & LG \\
\hline FG & $-0.926^{* * *}$ & $0.975^{* * *}$ & $0.885^{* * *}$ & $0.938^{* * *}$ \\
LG & $-0.807^{* * *}$ & $0.949^{* * *}$ & $0.753^{* * *}$ & \\
CVG & $-0.979^{* * *}$ & $0.914^{* * *}$ & & \\
GRI & $-0.933^{* * *}$ & & & \\
\hline *** Significant at $P<0.001$. & & &
\end{tabular}

on certain attributes of germination. Primed seeds were superior in FG, LG, CVG, and GRI, and it also decreased MGT such that the required time was faster with primed seed compared with normal seeds. Priming seed appeared to be able to completely overcome the effect of salt stress at 50 to $100 \mathrm{mM}$ and reduce the effect of salt at higher concentrations up to $200 \mathrm{mM}$. Seed priming can activate the metabolic processes within the seed to get early emergence of the radicle even under saline conditions. Our findings agree with Cantliffe [4] who found that priming seed in an osmotic solution may improve germination through metabolic activation involving the synthesis of nucleic acids, proteins, and enzymes, and increasing respiratory activity and energy reserve utilization. These findings are important for field situations where soil salinity is suspected as the use of priming could make the difference between successful field germination and establishment or substantial crop failure.

\section{Conclusion}

We conclude that the use of priming techniques can enhance the germination of wheat seed under saline conditions and under conditions of mild salt stress priming can entirely overcome the effect salt. We recommend conducting similar studies on other wheat varieties to investigate whether this is a general phenomenon. Additional work also needs to evaluate germination and early seedling growth under field conditions.

\section{References}

[1] V. Jajarmi, "Effect of water stress on germination indices in seven wheat cultivar," Proceedings of World Academy of Science, Engineering and Technology, vol. 49, pp. 105-106, 2009.

[2] S. Rafiq, T. Iqbal, A. Hameed, R. Zulfiqar Ali, and N. Rafiq, "Morphobiochemical analysis of salinity stress response of wheat," Pakistan Journal of Botany, vol. 38, no. 5, pp. 17591767, 2006.

[3] S. S. Lee and J. H. Kim, "Total sugars, $\alpha$-amylase activity, and germination after priming of normal and aged rice seeds," Korean Journal of Crop Science, vol. 45, no. 2, pp. 108-111, 2000.

[4] D. J. Cantliffe, "Seed enhancements," Acta Horticulturae, vol. 607, pp. 53-62, 2003.

[5] M. Iqbal, M. Ashraf, A. Jamil, and S. ur-Rehman, "Does seed priming induce changes in the levels of some endogenous plant hormones in hexaploid wheat plants under salt stress?" Journal of Integrative Plant Biology, vol. 48, no. 2, pp. 181-189, 2006.

[6] H. A. Khan, C. M. Ayub, M. A. Pervez, R. M. Bilal, M. A. Shahid, and K. Ziaf, "Effect of seed priming with $\mathrm{NaCl}$ on salinity tolerance of hot pepper (Capsicum annuum L.) at seedling stage," Soil \& Environment, vol. 28, no. 1, pp. 81-87, 2009.

[7] M. Ashraf and M. R. Foolad, "Pre-sowing seed treatment-A shotgun approach to improve germination, plant growth, and crop yield under saline and non-saline conditions," Advances in Agronomy, vol. 88, pp. 223-271, 2005.

[8] F. Carbineau and D. Come, "Priming: a technique for improving seed quality," Seed Testing International, no. 132, 2006.

[9] M. Z. Jafar, M. Farooq, M. A. Cheema et al., "Improving the performance of wheat by seed priming under saline conditions," Journal of Agronomy \& Crop Science, vol. 198, pp. 38-45, 2012.

[10] M. A. Kader and S. C. Jutzi, "Effects of thermal and salt treatments during imbibition on germination and seedling 
growth of sorghum at $42 / 19^{\circ} \mathrm{C}$," Journal of Agronomy and Crop Science, vol. 190, no. 1, pp. 35-38, 2004.

[11] M. A. Kader, "A comparison of seed germination calculation formulae and the associated interpretation of resulting data," Journal and Proceeding of the Royal Society of New South Wales, vol. 138, pp. 65-75, 2005.

[12] R. G. Steel, J. H. Torrie, and D. A. Dickey, Principles and Procedures of Statistics, a Biometrical Approach, McGraw Hill Book, Singapore, 3rd edition, 1997.

[13] M. Almansouri, J. M. Kinet, and S. Lutts, "Effect of salt and osmotic stresses on germination in durum wheat (Triticum durum Desf.)," Plant and Soil, vol. 231, no. 2, pp. 243-254, 2001. 

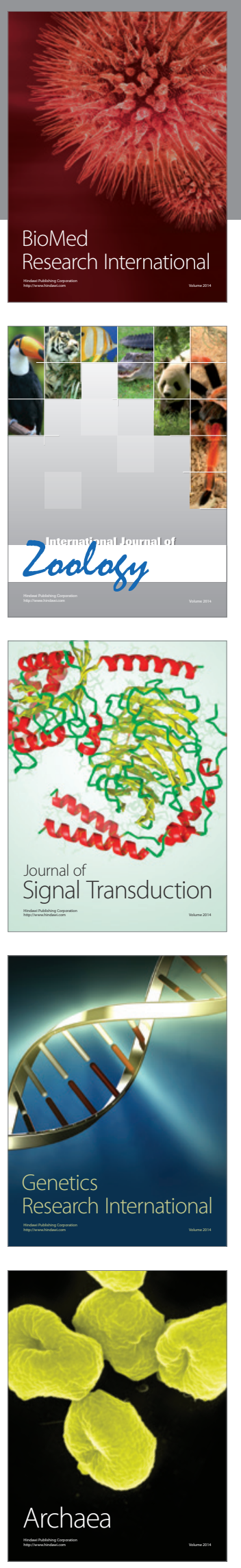
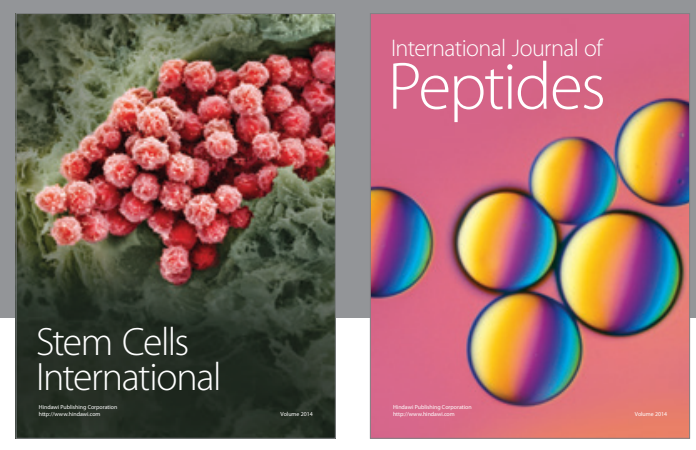

Submit your manuscripts at

http://www.hindawi.com
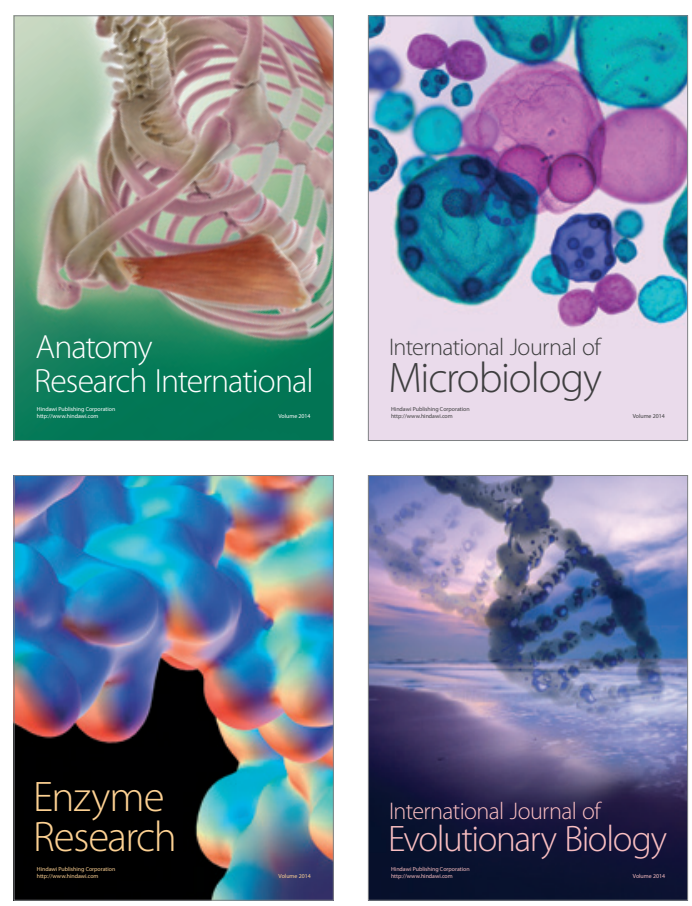
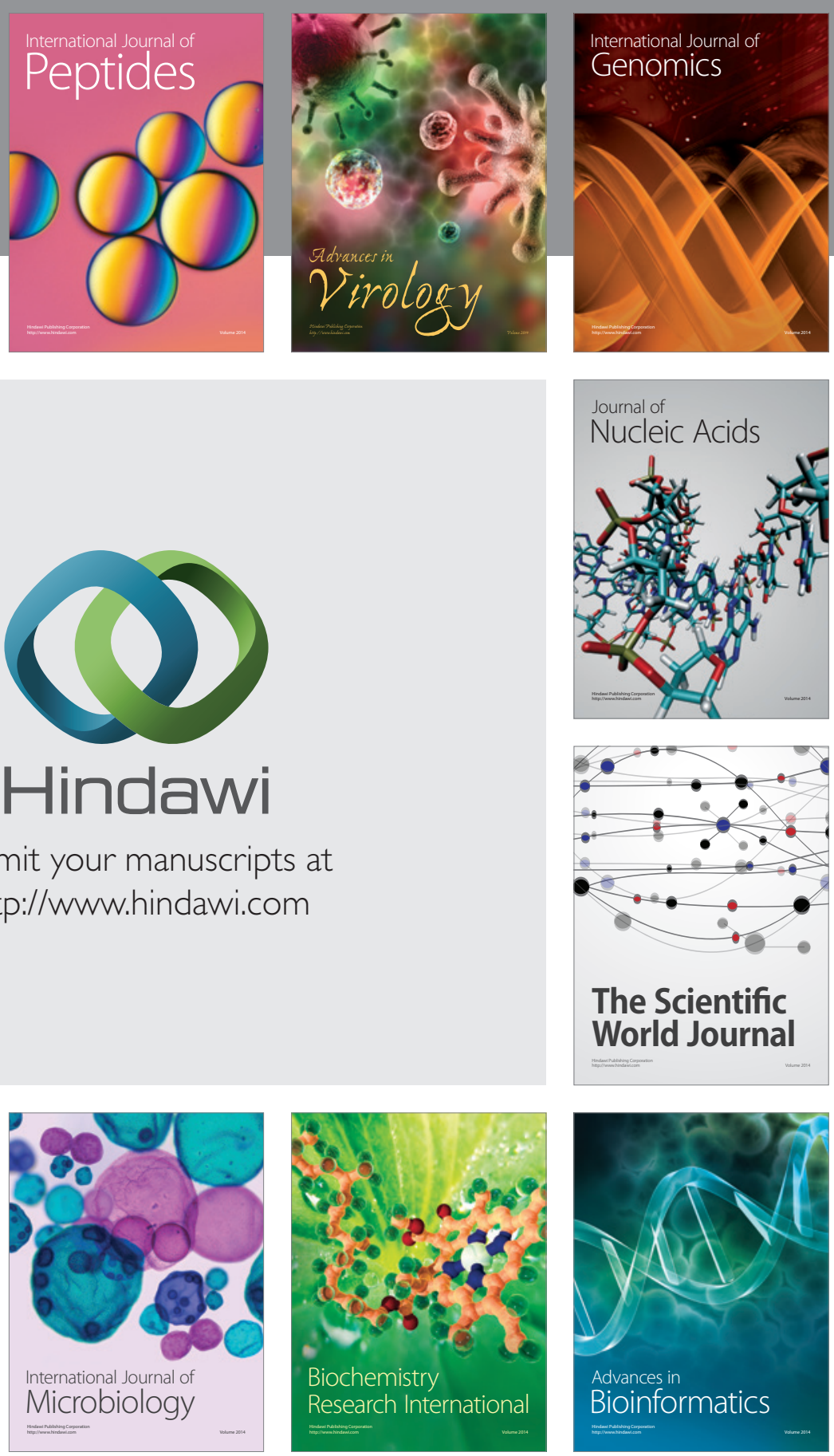

The Scientific World Journal
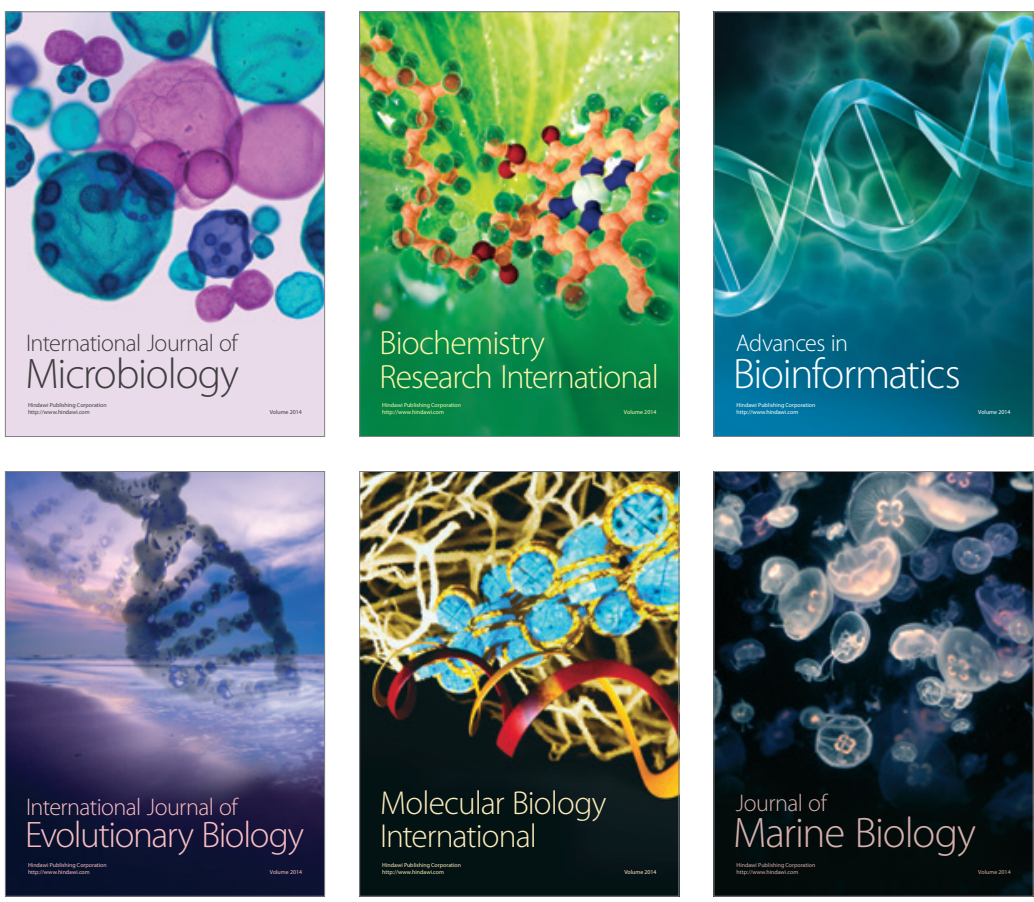